\title{
Board 108: Development of an Activity Centric Engineering Course to Teach Excel, MATLAB, and Engineering Math for High School Students (Work In Progress)
}

\section{Dr. Lynn A Albers, Hofstra University}

Dr. Lynn Albers is an Assistant Professor in Mechanical Engineering of the Fred DeMatteis School of Engineering and Applied Science at Hofstra University. Her previous academic contribution was as one of the founding five faculty/staff at Campbell University, helping the newly formed School of Engineering grow and establish roots in the community. A proponent of Hands-On Activities in the classroom and during out-of-school time programs, she believes that they complement any teaching style thereby reaching all learning styles. She earned her doctorate in Mechanical Engineering from North Carolina State University specializing in thermal sciences where her dissertation research spanned three colleges and focused on Engineering Education. Her passions include but are not limited to Engineering Education, Energy Engineering and Conservation, and K-20 STEM Outreach. Prior to matriculating at NCSU, she worked at the North Carolina Solar Center developing a passion for wind and solar energy research while learning renewable energy policy. She combined these passions with K-20 STEM Outreach while a National Science Foundation Fellow with the GK-12 Outreach Program at NCSU where she began Energy Clubs, an out-of-school-time program for third, fourth and fifth graders to introduce them to renewable energy.

\section{Dr. Richard J. Puerzer, Hofstra University}

Richard J. Puerzer is an Associate Professor of engineering at Hofstra University, where he is the Chairperson of the Engineering Department. 


\section{Development of an Activity Centric Engineering Course to teach Excel, MATLAB, and Engineering Math for High School Students (Work In Progress)}

\section{Background}

\section{First Stage of the Course Development}

In 2016, Hofstra University School of Engineering and Applied Science (hereafter referred to as "the university") wished to develop an engineering course for seniors in regional high schools. The university offers a required, first-year computer programming for engineers course, and an engineering design course. The computer programming course covers algorithms, logic, flowcharting and programming of solutions to engineering problems through the MATLAB environment and it was believed that this would be the desired course to roll out to the high schools. As an incentive to pilot the course, high school students were offered the opportunity to receive three credits from the university for successful completion of the material and satisfactory grades on the assessments. The cost to the student (their family) would be $\$ 390$ for the three credits and transcript. The three credits would be used to place out of the requirement at the university. The cost to the high school to pilot this course was $\$ 2000$ which included faculty support and intellectual property for the teacher during the academic year as well as a week of professional development for two teachers hosted by the university during the summer. It was not until the second year (2017-2018) that one student reported a large, public university accepted the three credits and he placed out of their equivalent computer programming class for engineers. The author recently learned that a second student received confirmation that the three credits will be accepted at another medium size, public university for Fall 2019 and she will place out of their equivalent computer programming class for engineers.

The above is based on the old model of the course which includes teaching sequentially from Dr. Craig Lent's book, "Learning to Program with MATLAB; Building GUI Tools," and giving three exams provided by the university at the end of the course. If the student passed the exams with an $80 \%$ or better, then they would receive the credit and official transcript from the university. The teachers created the lesson plans and taught the course at their respective schools.

\section{Second Stage of the Course Development}

The new model of the course being developed and taught at the university includes teaching globally using an active learning environment fostering computational and visual thinking by exposing the learner to Excel, MATLAB, and math. First-year students are introduced to Excel during the first few weeks of the course and then expected to complete official Microsoft Office Specialist Exam Certification in Excel through the university's IT student computing service. First-year students concurrently develop programming skills using MATLAB, and strengthen math skills through engineering applications.

Development of the new model began in August of 2018 and was first incorporated into the existing first year computer programming for engineers class at the university during the Fall 
2018 semester. New ideas, activities, and materials were tested. The successful ones were used in the Spring 2019 curriculum, while unsuccessful ideas were either redesigned or replaced. There are three sections of the course being offered this Spring. The author is currently teaching one section of the course $(\mathrm{N}=32)$ with the new material, another colleague is using the new material to teach a different section $(\mathrm{N}=16)$, and a third colleague is incorporating just the activities into their curriculum $(\mathrm{N}=30)$. This is the fourth time that the third colleague is teaching the course and is very much a sequential learner/teacher while the author and new model developer is very much a global learner/teacher ${ }^{5}$. Due to technology constraints in the classroom, the lecture material is prepared in PowerPoint.

Note that during this development period, the high school teachers were concurrently using a mix of the 2017-2018 curriculum and the new activities provided by the author. During the 20182019 academic year, there are 56 students taking an "engineering" course across four high schools of which 18 have paid $\$ 390$ for the university credit. Teachers are using three exams provided by the university to assess proficiency and impact on learning. A new rollout plan for the new model and curriculum is currently being defined. Once defined, we will look for funding. It is hoped that we can continue the program with the new curriculum starting with the 2019-2020 academic calendar.

\section{The Inspiration for the New Model}

The author was presented with the opportunity to create a high school engineering course in March of 2018. Prior to this, the author had the honor of teaching three courses designed with the intent to acclimate first-year students to engineering and to campus life. The courses were Living With the Lab, (LWTL) created by Dr. David Hall et al. at Louisiana Tech University ${ }^{7}$, Introductory Mathematics for Engineering Application, created by Dr. Nathan Klingbeil et al. at Wright State University (WSU) ${ }^{4}$, and a First-Year Seminar, created by Dr. Jennifer Latino at Campbell University. The first course demonstrated the need and effectiveness for active learning. The second course showed the importance of "filling the gaps" given the varied math curriculum offered between high schools. Teaching math basics using engineering applications also introduces students to a variety of engineering curricula in their first semester. The third course taught the importance of engaging students in team building, networking, learning about the university (library, tutoring services, etc.), and better understanding themselves.

"Because students enter their first-year with varied math (and computer) backgrounds, the university needs a course meant to help fill the gaps. In other words, every student enters their first year in a boat filled with holes. The course helps fill each hole so that at the start of the next semester, all boats can rise with the tide."

This need has resulted in the re-development of the first-year computer programming for engineers course. The author imagined ideas and ways to recreate this course starting in March and was able to plan and develop an idea in August. The course is activity centric with learning objectives written up in modules. The learning objectives are from three key areas: Excel, MATLAB, and math. The activities provide an opportunity for students to collaborate, network, and collect data. The modules focus on a way to teach concepts in Excel, MATLAB, or Math 
using that data. To infuse flexibility into the curriculum, the modules are applicable to different activities as long as the data lends itself to the lesson at hand. Threaded throughout the course are assignments to help the students learn about themselves and their learning styles.

Having taught Living With the Lab, the author saw first-hand how a project-based learning ${ }^{7}$ curriculum positively impacts and motivates students. The author did not have the resources to implement the LWTL projects in the redesigned course so the "smaller-scale" in class activities were decidedly a better fit. The results from Salzmann et al. deemed it necessary to implement a hybrid of the two courses where the focus would be primarily on the activity and not on the math $^{8}$. Hence, the new model involves starting with an activity and incorporating the math, Excel, and MATLAB afterwards.

\section{The New Model}

The new model is being created for both first-year engineering students at the university and high school seniors. The course objectives include an introduction to Excel, introductory programming using the MATLAB environment, and reviewing core math for engineers. The course learning outcomes include proficiency in Excel and MATLAB such that students can effectively input, store, sort, plot, and output data. Math outcomes include the ability to mathematically model data, develop systems of equations, and properly define vectors. To accomplish this, activities are performed to reinforce the mathematical concept, collect applicable data or systems of equations to teach Excel and MATLAB, and engage students in collaborations with their colleagues. Figure 1 shows the new model where the activities are the driving force from which math, Excel, and MATLAB are learned.

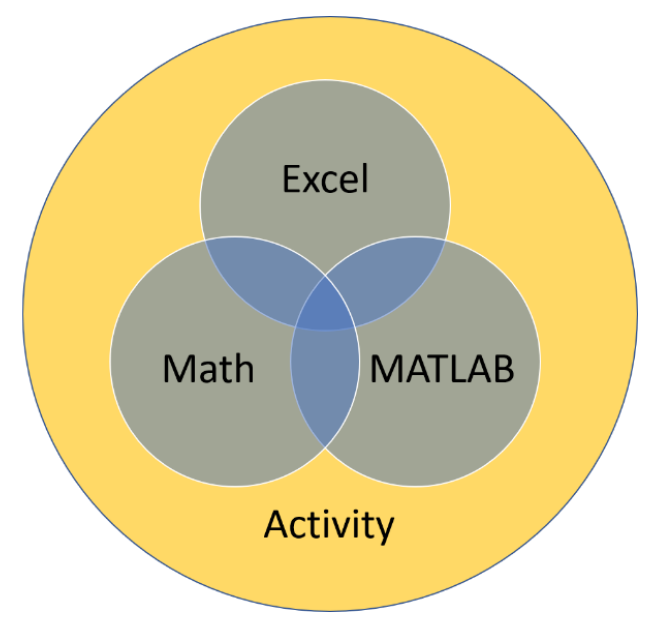

Figure 1 The new, activity centric model

\section{An Example}

On the first day of class, students engaged in the activity, Bungee Barbie and Kamikaze Ken developed at Indiana University, Bloomington, $1995^{2}$. This activity is designed to teach linear mathematical modeling and graphing. The data from the activity was first plotted by hand and used to calculate the slope, y-intercept, and linear mathematical model (Lecture 2). Then, the 
same data was inputted into Excel, calculations were performed, and graphs were created (Lecture 3). Once again, the same data was stored in MATLAB via vector variables and plotted using simple plot commands (Lecture 4). Finally, the data was used to teach the linear leastsquares fitting technique, and trendlines were added in Excel and MATLAB (Lecture 5). Students were not expected to be familiar with either Excel or MATLAB at this time.

The purpose of having them plot the data by hand (Lecture 2) is to introduce them to the idea of fitting data to a mathematical model so that more information can be extrapolated from it. Students are introduced to the idea of a "best fit" line which happens to be linear in this instance. From informal teaching observations, there are always a handful of students for whom independent vs. dependent variables is new terminology while others need reminders that the independent variable (the number of rubber bands) fits the $\mathrm{x}$-axis while the dependent variable (distance in $\mathrm{cm}$ ) fits the y-axis. No matter how often it is announced, there will always be groups who measured the distance in inches, not $\mathrm{cm}$. Thus, the activity is a great way to "fill gaps" and make sure everyone moves forward with the same understanding of collecting, modeling, and plotting data.

Plotting the data by hand should be familiar and comfortable for the students assuming this has been done by them many times in high school. By giving them a familiar task in their first engineering course, it is hypothesized that this reduces their anxiety towards engineering. Transitioning to Excel is not as difficult knowing what the plot should look like. Successfully plotting in Excel and then in MATLAB helps introduce the student to both tools while reducing the fear-factor of each tool.

Comparison with a model of the WSU Introductory Mathematics with Engineering Applications course to show uniqueness of the new model.

\section{Figure 2 The other course Model}

The Wright State University course "provides an overview of the salient math topics most heavily used in the core sophomore-level engineering courses." "The course will also provide an introduction to the engineering analysis software Matlab, which is used throughout the engineering curriculum. While time constraints will preclude a formal treatment of Matlab during lecture, application of the software will be integrated with each laboratory assignment."4

Having taught the WSU concerned the new model course too closely. Since increasing student success in engineering, it that the new model be visualization of the WSU are the driving force with reinforcing the math. the author concludes (at

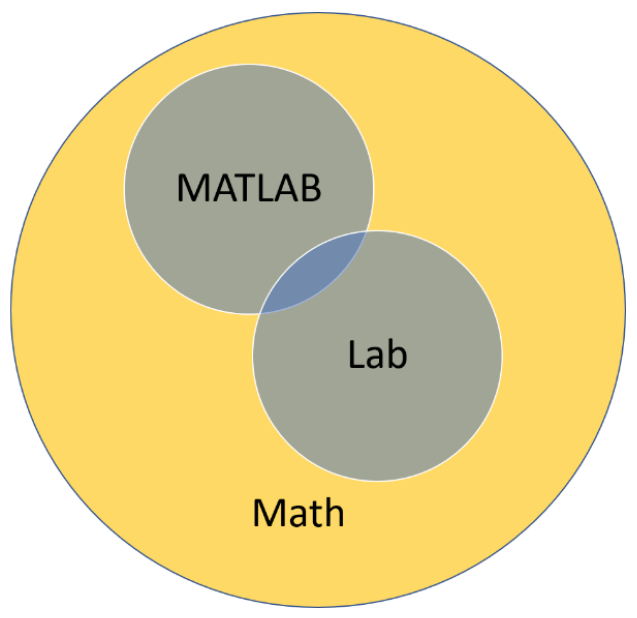

course, the author was might resemble the WSU both courses have a goal of retention, motivation, and was important to the author unique. Figure 2 is a course where math lectures the labs and MATLAB Comparing Figures 1 and 2, this time) that the new 
model is different and will continue developing it until further literature reviews reveal otherwise.

\section{Continuing Work}

An unexpected revelation was that an activity centric course such as this is more global and less sequential in imparting knowledge. Therefore, it is hypothesized that this new model will appeal to and help retain students who are naturally global learners.

The redesign, search for activities, and development of modules satisfying the learning objectives in Excel, Math, and MATLAB took the bulk of the time in the Fall 2018 semester. Because the course was under development, the students were not surveyed for their perception of learning. Students will be assessed at the end of the Spring 2019 semester through reflective narrative and a comparison of course grades vs. learning styles. All students completed the Index of Learning Styles Questionnaire ${ }^{6}$ at the beginning of the semester.

A long-term assessment of the impact of learning using this new model by looking at retention and performance as the student progresses through the university's curriculum is still under development.

The goal is to have 6-10 activities with corresponding modules helping to teach Excel, MATLAB, and math needed for the student to succeed in engineering. Three activities from the previous semester are returning while three new ones are being developed with colleagues this semester. In addition, the high school teachers are adapting their activities to include math, Excel, and MATLAB learning objectives.

If the new model rolls out into the high schools, it would be interesting to track the number of students continuing to grades 13-16 and their major. In other words, does the course motivate students to become engineers?

A new form of assessment is under development. Currently, two midterm exams and one final exam are given to assess knowledge gained. They have a format of multiple choice $(30 \%)$, short answer (10\%), and coding scripts or work in Excel (60\%).

\section{Professional Development}

The tentative plan for teacher professional development involves following the method as defined and successfully implemented by Burghardt et al. ${ }^{3}$ At the end, they will become certified to assess student proficiency in the course. They will be empowered to teach the course and assign a final grade determining if the student should receive credit from the university.

\section{Conclusion}

There is a great deal of work that still needs to be done. The success of two students being granted credit for the course at two, different universities bodes well for the program which will try to build on the momentum. Having visited the four high schools, there is a need for this course and a desire from them to continue collaborating with the university. The author is aware that the NSF funded high school engineering curriculum E4USA is being developed, 
implemented, and tested concurrently. However, the author believes that this course will complement that curriculum with no intentions of competing with E4USA.

\section{References}

1. Albers, L. A. (2018). Implementing the Wright State Model First-Year Engineering Mathematics Course in a Startup School of Engineering. American Society for Engineering Education Conference Proceedings.

2. Bungee Barbie \& Kamikaze Ken - Indiana University Bloomington. (1995). Retrieved from http://www.indiana.edu/ hmathmod/doc/bungeeb5.doc

3. Burghardt, M. D., \& LLewellyn, M. (2006). Engineering Effective Middle School Teacher Professional Development. American Society for Engineering Education Conference, 11.558.1 - 11.558-12.

4. College of Engineering and Applied Sciences, W. S. U. (Ed.). (2019). Engineering Mathematics (EGR 1010) Topics and Materials. Retrieved from https://engineering-computer-

science.wright.edu/research/engineering-mathematics-topics-and-materials

5. Felder, R. M., \& Silverman, L. K. (1988). Learning and Teaching Styles In Engineering Education. Engineering Education, 78(7), 674-681.

6. Felder, R. M., \& Soloman, B. A. (1996). Index of Learning Styles Questionnaire. Retrieved from https://www.webtools.ncsu.edu/learningstyles/

7. Living with the Lab Faculty Team, L. T. U. (Ed.). (2018). living with the lab; boosting hands-on learning in engineering education. Retrieved from http://www2.latech.edu/ kcorbett/LWTL/home/main.html

8. Salzman, N., \& Hunt, G. (2016). Modification and Assessment of a First-Year Engineering Course to Improve Students' Calculus Readiness. First Year Engineering Experience (FYEE) Conference, W1A-1 W1A-4. 